\title{
IbM ASAH KREATIVITAS ANAK DENGAN PENGENALAN KENDALI RASPBERRY PI
}

\author{
Angga Prasetyo ${ }^{1^{*}}$, Yovi Litanianda ${ }^{2}$ \\ ${ }^{1,2}$ Fakultas Teknik, Universitas Muhammadiyah Ponorogo, Indonesia \\ 1angga_raspi@umpo.ac.id, ${ }^{2}$ yovi@umpo.ac.id
}

\begin{abstract}
ABSTRAK
Abstrak: Umumnya kita ketahui bahwa selama ini anak-anak terlanjur dengan dimanjakan oleh komputer canggih dan punya penampilan menarik seperti iPad, Mac, Window yang pada dasarnya anak-anak ingin bereksperimen dengan komputer yang mereka miliki, tetapi mereka merasa takut apabila terjadi kerusakan. Tingginya minat dari siswa untuk mengeksplorasi dirinya dalam bidang teknologi khususnya di bidang komputer, maka dibutuhkan pelatihan sebagai bekal informasi seperti Raspberry. Pelatihan pengenalan mikro komputer raspberry pi bertujuan untuk mengenalkan proses kendali input output terhadap perangkat keras dari pendekatan interaksi bahasa pemrograman phyton meliputi, mulai dari tahap instalasi, pegenalan general purpose input output (GPIO), fungsional port perangkat, proses interaksi contohnya: resistor, LED, project board, $L C D$, relay, motor DC, robotic serta mengendalikannya dengan smartphone. Pendekatan pengenalan mikrokomputer dan bahasa pemrograman python memacu kreativitas untuk menciptakan suatu kendali perintah bagi perangkat keras, serta mampu mendeskripsikan kecerdasan buatan pada perangkat robotic.
\end{abstract}

Kata Kunci: Raspberry, Pelatihan, input output, robotic.

\begin{abstract}
We generally know that all children have been pampered by sophisticated computers and have an attractive appearance such as iPad, Mac, Window which basically kids want to experiment with the computer they have, but they feel Fear of damage. The high interest of students to explore themselves in the field of technology, especially in the field of computer, it takes training as a provision of information such as Raspberry. Raspberry Pi Micro Computer Recognition training aims to introduce the process of input control output to the hardware of a Python programming language interaction approach, ranging from the installation stage, the general purpose input Output (GPIO), functional device port, interaction process For example: resistor, LED, project board, LCD, relay, DC motor, robotic and control it with smartphones. The approach to microcomputer recognition and the Python programming language promotes creativity to create a control of commands for hardware, and is capable of describing artificial intelligence on robotic devices

Keywords: Raspberry, training, input output, robotic
\end{abstract}

\section{A. LATAR BELAKANG}

Sekolah menengah pertama Muhammadiyah I Ponorogo (SMP Muhipo) merupakan salah satu SMP di ponorogo yang berada dibawah naungan Muhammadiyah atau lebih dikenal dengan SMP Muhipo berada di Jl. Batoro Katong No. 6-A, Banyudono, Kec. Ponorogo. Dalam meningkatkan prestasi dan mutu lulusan SMP Muhipo berusaha memberikan pelayanan yang bagus dalam bidang pendidikan yang diharapkan para siswa sudah dibekali dengan keahlian dan ketrampilan di bidang teknologi dan informasi (Cholik, 2017). Selain pendidikan yang ada di internal sekolah, SMP Muhipo juga mendukung siswanya untuk aktif dalam mengikuti kegiatan pembelajaran di luar sekolah. Salah satu kegiatan pembelajaran 
di luar sekolah adalah dengan mengikuti workshop, seminar dan komunitas.

Saat ini teknologi dan informasi berkembang pesat, hampir semua orang menggunakan teknologi dalam membantu pekerjaan sehari-hari contohnya: smartphone, personal computer (Cobantoro, 2018; Masykur, 2016; Prasetyo \& Setyawan, 2018). Smartphone merupakan perangkat yang bisa dikatakan dengan istilah "sudah jadi", sehingga kurang mengakomodasi generasi muda untuk membuat suatu inovasi (Rahma, 2015). Dalam proses menghasilkan suatu inovasi diperlukan pengenalan teknologi, untuk membentuk generasi inovatif sejak dini sangat diperlukan solusi untuk menstimulus generasi muda agar dapat membuat dan menciptakan kontribusi positif pada pengembangan teknologi (Nurizzati, 2018).

Raspberry Pi merupakan device embedded system dalam jenis single Board computer. Raspberry $\mathrm{Pi}$ memiliki system on chip Broadcom bcm2835 dengan prosessor ARM1176JZF-S $700 \mathrm{MHz}$ (Farrid Christianti et al., 2015). Raspberry Pi dapat diinstal sistem operasi yang support dengan teknologi ARM seperti Raspbian OS, Arch Linux. Bahasa pemrograman menggunakan pyhton sebagai perintah. Bentuk Raspberry dapat dilihat pada Gambar 1 berikut.

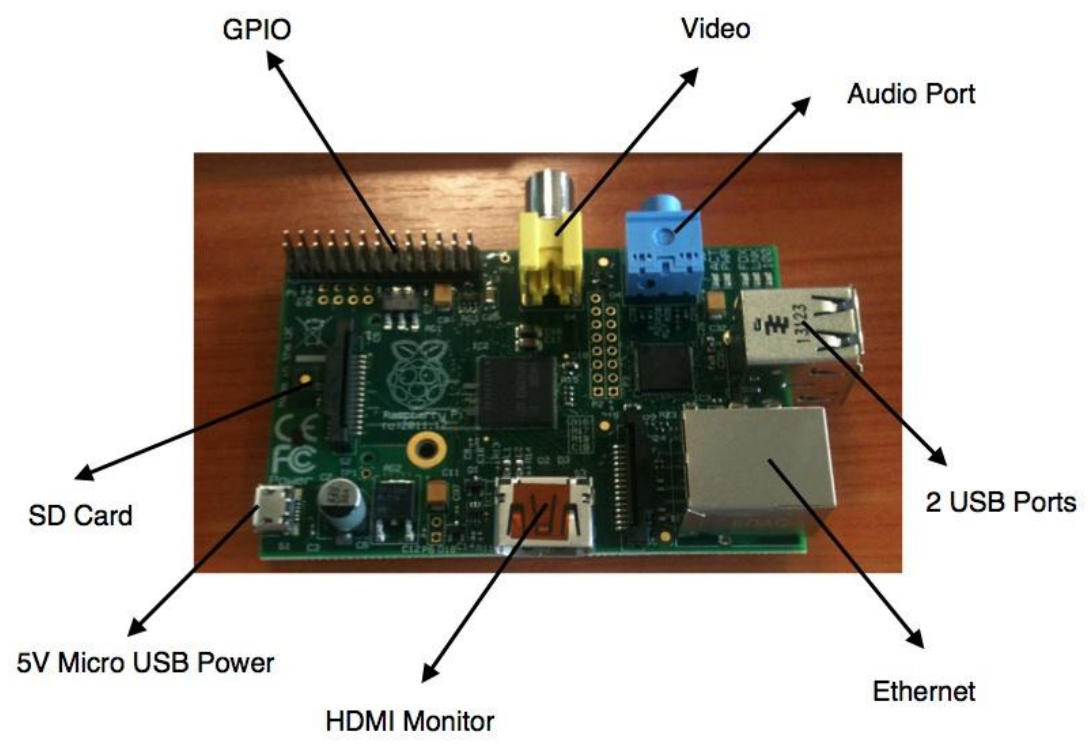

Gambar 1. Raspbery Board

Seperti kita ketahui selama ini anak-anak terlanjur dengan dimanjakan oleh komputer canggih dan punya penampilan menarik seperti iPad, Mac, Windows. Tapi, keindahan komputer itu tak membuat mereka jago komputer, pada dasarnya anak-anak ingin bereksperimen dengan komputer yang mereka miliki, tetapi mereka merasa takut apabila terjadi kerusakan. Ancaman ini membuat kurang kreatif dalam mengembangkan keahliannya (Cobantoro \& Anugra, 2017; Cobantoro, Setyawan, \& Budi Wibowo, 2019). Dibutuhkan teknologi sederhana yang mudah dipelajari dalam bereksperimen yaitu menggunakan Raspberry. Tingginya minat dari siswa SMP Muhipo dalam mengeksplorasi dirinya dalam bidang teknologi khususnya dibidang komputer, maka dibutuhkan pelatihan sebagai bekal seperti Raspberry. Dari latar belakang permasalahan di atas maka kami dari tim pengabdian unmuh ponorogo mamberikan solusi yang dituangkan 
dalam bentuk pelatihan yang di beri tema "Asah Kreativitas Anak Dengan Pengenalan Kendali Raspberry PP'.

Secara umum yang menjadi permasalahan mitra adalah:

1. SMP Muhipo memebutuhkan mitra untuk memeberikan pelatihan kertampilan yang diperlukan dalam membangun jiwa kreatifvitas siswanya.

2. Perangkat Raspberry masih belum terkenal di masyarakat luas.

3. Minimnya guru atau ahli di bidang Raspberry di SMP Muhipo sehingga perlu diadakan pelatihan tentang Raspberry untuk siswanya dengan menggandeng mitra.

4. Perlunya ketrampilan tambahan diluar jam pelajaran untuk membekali siwanya iptek untuk lulusan.

5. Diperlukannya mitra kerja sama demi tercapai nya visi dan misi SMP muhipo.

\section{B. METODE PELAKSANAAN}

Setelah menganalisa situasi dan memperhatikan permasalahan yang dihadapi maka solusi yang ditawarkan adalah "Asah Kreativitas Anak Dengan Pengenalan Kendali Raspberry PI". Melakukan sosialisasi ke SMP Muhipo dan mengadakan pelatihan menyangkut penggunakan pengenalan alat serta fungsi dan cara penggunakan rashberry secara detail dan mahir kepada siswanya. Serta Melakukan evaluasi dan pendampingan setelah pelatihan. Adapun metode kegiatan yang dilakukan adalah :

1. Pembuatan kepanitiaan kegiataan.

2. Memberikan proposal dan mou kepada SMP Muhipo menyangkut akan diadakan pelatihan perangkat Raspberry.

3. Membuat team pakar ahli di bidang perangkat Raspberry dari universitas sebagai pendamping peneliti dalam menyampaikan materi.

4. Membuat kisi kisi tentang pelatihan yang dilakukan menyangkut pengenalan perangkat serta pemrograman dasar pada Raspberry.

5. Membuat buku panduan tentang penggunakan perangkat Raspberry.

6. Membuat jadwal dan lokasi di adakan pelatihan perangkat Raspberry.

7. Membuat evaluasi dari hasil pelatihan terhadap peserta pelatihan Raspberry.

8. Menyelenggarakan pelatihan Raspberry bagi siswa SMP Muhipo.

Materi disampaikan dalam bentuk praktek (90\%). Diharapkan perserta Pelatihan dapat terus mengembangkan kemampuan pemrogramannya setelah kegiatan. Materi pelatihan yang akan disampaikan adalah sebagai berikut:

1. Struktur dasar Raspberry dan prinsip kerja perangkat.

2. Teknik pemrograman Raspberry.

3. Interfeshing input dan output.

4. Aplikasi sederhana. 


\section{HASIL DAN PEMBAHASAN}

Kegiatan pengabdian kali ini, difokuskan pada siswa sekolah menengah pertama (SMP) muhammadiyah Ponorogo. Pelaksanaan dimulai dari peninjauan tim ke lokasi mitra untuk mengetahui kondisi serta kebutuhan transfer teknologi kepada para siswa, dari hasil kunjungan dicapai kesepakatan bahwa perlu dilakukan pelatihan yang mampu memunculkan kreativitas mengarah pada pemanfaatan teknologi informasi. Pelatihan pengenalan mikro komputer raspberry pi bertujuan untuk mengenalkan proses kendali input output terhadap perangkat keras dari pendekatan interaksi bahasa pemrograman phyton. Pelaksanaan kegiatan pelatihan raspberry pi meliputi :

1. Pengenalan mikro komputer raspberry mulai dari tahap instalasi, pegenalan general purpose input output (GPIO), fungsional port perangkat.

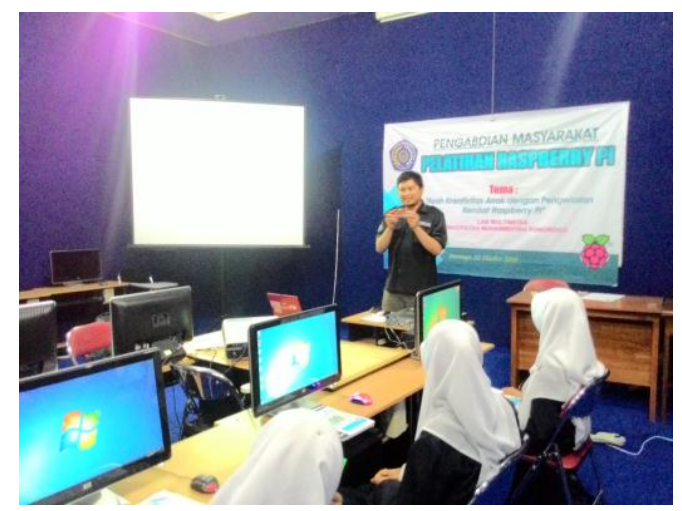

Gambar 2. pengenalan Board Raspberry

2. Proses pendekatan memperkenalkan bahasa pemrograman python sebagai alat komunikasi antara perangkat keras dan raspberry pi, pada kegiatan ini siswa berusaha untuk memahami dan bisa menuliskan perintah if, or, while, else, and.

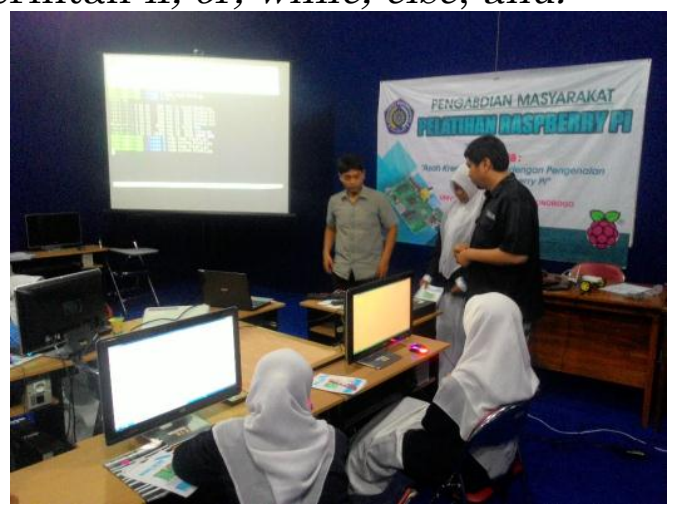

Gambar 3. Pengenalan Interaksi IO 


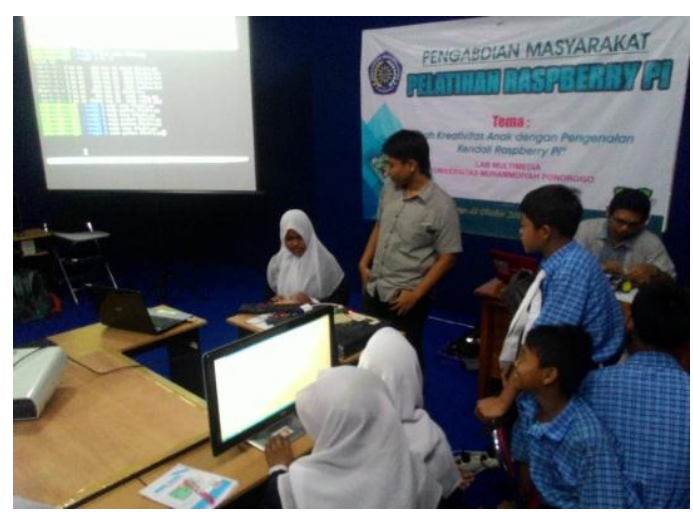

Gambar 4. Praktek Input Output

3. Proses pembuatan project cerdas input output kegiatan ini terdiri dari pengenalan alat-alat yang dibutuhkan dalam proses interaksi contohnya : resistor, $L E D$, project board, $L C D$, relay, motor $D C$

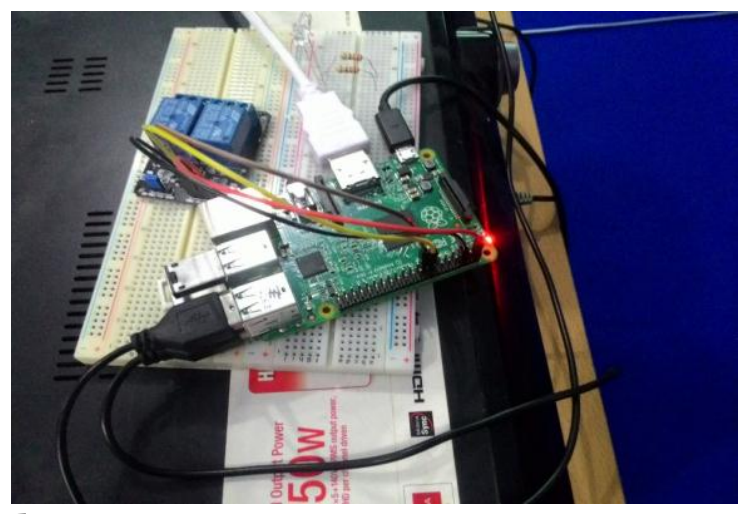

Gambar 5. Hasil Kendali relay pada raspberry

4. Pengenalan kecerdasan buatan dengan memahami proses robotic serta mengendalikannya dengan smartphone.

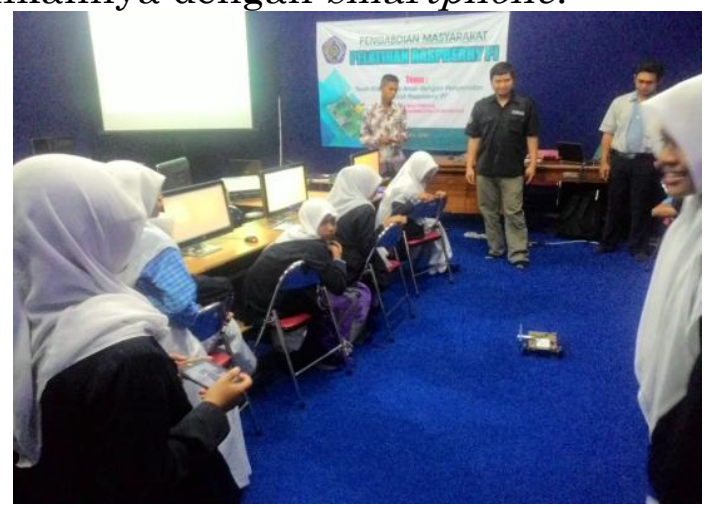

Gambar 6. Praktek kendali robot dengan perangkat smartphone

\section{SIMPULAN DAN SARAN}

Dari seluruh kegiatan pelatihan raspberry pi pada siswa SMP muhammadiyah 1 ponorogo, dapat disimpulkan pendekatan pengenalan mikrokomputer dan bahasa pemrograman python memacu kreativitas untuk menciptakan suatu kendali perintah bagi perangkat keras, serta mampu mendeskripsikan kecerdasan buatan pada perangkat robotic

Sasaran selanjutnya, agar kegiatan pelatihan dapat terus berlanjut diharapkan lebih ditekankan pada proses pembuatan purwarupa perangkat, yang nantinya dapat menghasilkan kontribusi untuk membantu menyelesaikan pekerjaan manusia. 


\section{DAFTAR RUJUKAN}

Cholik, C. A. (2017). Pemanfaatan Teknologi Informasi dan Komunikasi untuk Meningkatkan Pendidikan di Indonesia. Syntax Literate; Jurnal Ilmiah Indonesia, 2(6), 21-30.

Cobantoro, A. F. (2018). Analisa QoS (Quality of Service) Pada Jaringan Rt-Rw Net Dengan Kendali Raspberry Pi. Network Engineering Research Operation, 4(1). https://doi.org/10.21107/nero.v4i1.109

Cobantoro, A. F., \& Anugra, F. G. (2017). Designing Parking System-Based Vb.Net and MySQL Using Radio Frequency and Identification (RFID). VOLT: Jurnal $\begin{array}{lllll}\text { Ilmiah Pendidikan Teknik } & \end{array}$ https://doi.org/10.30870/volt.v2i2.2009

Cobantoro, A. F., Setyawan, M. B., \& Budi Wibowo, M. A. (2019). Otomasi Greenhouse Berbasis Mikrokomputer Raspberry PI. Jurnal Ilmiah Teknologi Informasi Asia, 13(2), 115. https://doi.org/10.32815/jitika.v13i2.360

Farrid Christianti, R., Puspamelati, N., Kurnianto, D., kunci, K., Pi, R., \& Server, W. (2015). Aplikasi Raspberry Pi Pada Telerobot Pembersih Lantai. Universitas Muhammadiyah Purwokerto Purwokerto, 978-602.

masykur, fauzan. (2016). Aplikasi Rumah Pintar (Smart Home) Pengendali Peralatan Elektronik Rumah Tangga Berbasis Web. Jurnal Sains Dan Teknologi Industri, 14(1), 93-100.

Nurizzati, S. K. dan Y. (2018). Dampak Penggunaan Teknologi Informasi dan Komunikasi Terhadap Perilaku Sosial Siswa di MAN 2 Kuningan. Edueksos, VII(2), 161-176.

Prasetyo, A., \& Setyawan, M. B. (2018). Purwarupa Internet Of Things Sistem Kewaspadaan Banjir Dengan Kendali Raspberry PI. Network Engineering Research Operation, 3(3). https://doi.org/10.21107/NERO.V3I3.97

Rahma, A. (2015). Pengaruh Penggunaan Smartphone Terhadap Aktifitas Kehidupan Siswa. Jurnal Fisip, 2(2), 1-12. 